\title{
Idéias, interesses e mudanças institucionais
}

Jorge R. B. Tapia e Eduardo R. Gomes

Introdução

Este trabalho é uma discussão da relação entre instituições, interesses e idéias, tendo como referência empírica as experiências de concertação social na Europa desde os anos de 1990.

Assim, à luz da literatura internacional recente, argumentamos que, diferentemente das primeiras análises sobre as relaçôes das idéias com a dinâmica dos interesses e das instituições, o debate atual tem incorporado uma maior complexidade no entendimento dessa interação, interpelando algumas visōes correntes da ciência política. Enfatizando as relações entre mudança econômica, instituiçôes, paradigmas e aprendizado social, as novas contribuições ressaltam a importância da dimensão cognitiva dos processos políticos na tentativa de construir abordagens mais ricas e adequadas sobre os fenômenos em pauta.

Nesse sentido, embora inovadora, a ênfase dada até agora ao papel das idéias ainda não parece ser suficiente para explicar a difusão e a natureza dos processos de reformas econômicas e sociais, sua legitimidade ou sustentação no plano político. É preciso que o processo de adoção das idéias produza resultados avaliados positivamente, oferecendo respostas, mesmo que não consensuais, para questôes consideradas centrais na agenda pública. Ademais, há um complexo processo de aprendizado e de mimicking ${ }^{1}$ no

1. Mímica, imitação mantido no original em inglês. 
âmbito das políticas e das reformas econômicas e sociais que permite elucidar intrincados desdobramentos, não podendo portanto ser desconsiderado, inclusive porque talvez permita adicionar novas dimensōes às abordagens das reformas econômicas e sociais inspiradas nas instituições ou na competição política.

Este trabalho está organizado em quatros partes. A esta introdução se segue uma parte dedicada à discussão teórica, na qual sublinhamos as contribuiçôes recentes ao debate sobre o papel das idéias nos processos de reforma econômica e social. Depois, procuramos ilustrar os conceitos teóricos à luz das experiências de concertações sociais de segunda geração na Europa. Na quarta e última parte, rediscutimos os principais aspectos teóricos destacados ao longo do trabalho.

Idéias, interesses, instituições e paradigmas

Nas últimas décadas, no campo da ciência política, têm adquirido importância e rápida difusão os enfoques institucionalistas, cuja variedade foi apropriada com rigor pelo trabalho de Hall e Rosemary (1996). Dados os propósitos deste estudo, optamos por abordar o tema resgatando as perspectivas do institucionalismo na sua intersecção com as políticas públicas, privilegiando como eixo as relações entre instituições e idéias no contexto mais amplo das experiências de reformas tanto no âmbito econômico como no social (cf. Immergut, 1996).

Os trabalhos de Heclo (1974) e de Peter Hall $(1989,1993,1997)$ representam as contribuições mais consistentes na perspectiva do institucionalismo histórico, e defendem um papel-chave das idéias na determinação dos resultados obtidos pelas instituiçōes. Inspirado no livro clássico de Thomas Kuhn, Peter Hall em essência afirma que "uma política é feita dentro do contexto de um paradigma de políticas públicas". Esse esquema é internalizado pelos políticos, administradores governamentais, analistas políticos, entre outros agentes decisórios relevantes, razão pela qual surge um conjunto legítimo de técnicas políticas, mecanismos e instrumentos que delimitam os objetivos e os alvos da política pública.

Como discute Hall (1989) no seu clássico estudo sobre a difusão das idéias keynesianas, esse movimento analítico está longe de representar um desdobramento comum, como explicação de por que as idéias se difundem mais em alguns países e menos em outros. Hall identifica três perspectivas de análise que procuram determinar as causas da emergência das idéias 
keynesianas no período pós-1930, quais sejam, aquela centrada na economia, aquela centrada no Estado e aquela centrada em coalizões, cada uma com uma concepção particular sobre a importância de determinadas dimensôes explicativas.

Assim, no enfoque centrado na economia, enfatiza-se o papel desempenhado pelo conhecimento especializado (particularmente aquele detido pelos economistas) e os impactos produzidos entre os formuladores de políticas, resultando em mudanças na concepção e na implementação de determinadas políticas públicas. Mais especificamente, o papel das idéias nesse enfoque reside na sua capacidade de persuasão no âmbito de uma determinada rede de compartilhamento de políticas por economistas profissionais e por formuladores de políticas, característica essa associada à própria qualidade das idéias, dados os diagnósticos e as soluçôes concretas que apresentam para problemas centrais em determinados momentos históricos.

Contudo, parece haver uma excessiva ênfase no papel dos economistas e dos próprios assessores especializados na dinâmica do fazer políticas públicas, pois, como o próprio Hall (1989) demonstrou, a influência dos economistas variou significativamente no tempo e entre os diferentes países. Sem dúvida, o caráter persuasivo das idéias é um aspecto extremamente importante, como têm destacado as correntes da chamada perspectiva cognitiva das políticas públicas, porém as idéias estão situadas num campo relacional no qual há a disputa com outras idéias e, para sua viabilidade, é preciso incorporar outras dimensões explicativas, como veremos mais adiante.

O enfoque centrado no Estado, por sua vez, elaborado a partir do artigo seminal de Weir e Skocpol (1985), o qual está fortemente identificado com a obra de Peter Evans, oferece uma maneira diversa de explicar o papel das idéias no processo de mudança política. Dessa perspectiva, a difusão de novas idéias dependerá da configuração institucional do Estado e da experiência prévia com políticas relacionadas com elas. No âmbito da formulação de políticas, a relativa abertura das instâncias decisórias à influência de consultores externos, economistas, pode acelerar a incorporação de novas idéias e proposições às políticas públicas.

Além disso, a orientação adotada implicitamente na divisão institucional de responsabilidades entre os diferentes ministérios e órgãos governamentais será crucial para a recepção de novas idéias pelas instâncias decisórias fundamentais dentro do governo. Um último elemento destacado pela abordagem centrada no Estado é o papel incentivador ou inibidor na adoção de 
novas idéias, associado à existência de qualificaçōes da burocracia estatal. Quando essas qualificaçôes estão presentes, aumenta em muito a probabilidade de que novas idéias e propostas sejam incorporadas, e a percepção de fragilidades na capacidade institucional tende a reforçar resistências contra a assimilação de novas idéias.

A principal contribuição desse enfoque é resgatar a relevância e o papel das estruturas institucionais do Estado, a influência da cultura institucional, as características do sistema estatal e da sua efetiva capacidade de implementação de novas idéias e propostas. Esses aspectos são relevantes porque relativizam, inclusive, o uso abusivo da noção de inovação, muitas vezes sinônimo de fazer uma coisa de maneira diferente. Com isso, são oferecidas ferramentas analíticas que permitem explicar uma variação através dos países da recepção das idéias keynesianas, enfatizando as distintas configurações institucionais dos Estados e a importância das experiências prévias das políticas em cada país. Por outro lado, esse enfoque padeceria de uma ênfase excessiva no papel das burocracias públicas e de uma simétrica negligência em relação ao papel desempenhado pelos políticos. Essa superestimação do Estado conduziria, segundo Hall, a uma visão imutável da própria dinâmica das instituiçôes.

Finalmente, o enfoque centrado em coalizões procura explicar o papel das idéias e das próprias políticas no âmbito mais amplo do sistema político. Aqui, as referências são os trabalhos desenvolvidos por Peter Gourevitch (1986), cuja ênfase está na assertiva de que as políticas públicas precisam mobilizar suporte entre coalizões de interesses econômicos mais amplos, dos quais dependem os votos dos políticos e o bem-estar dos eleitores. Portanto, o desafio é a formação de coalizões de interesses políticos, econômicos e sociais capazes de persuadir os formuladores dos benefícios associados a determinadas opçôes de políticas públicas. Essa perspectiva, aplicada ao caso da difusão das idéias keynesianas como resposta aos desafios trazidos pela grande depressão dos anos de 1930, significa que a explicação da maior ou menor difusão está na habilidade de cada regime político de construir coalizões de sustentação aos novos experimentos de tipo keynesiano dentro das políticas deflacionárias.

A contribuição da abordagem centrada em coalizões é recolocar a importância da análise da dinâmica da política no âmbito das relações do conjunto do sistema político, no qual encontramos as diferentes modalidades de articulação de interesses que refletem as clivagens existentes nas diferentes sociedades. Isso é particularmente importante no caso da política econômi- 
ca, que afeta de maneira direta interesses materiais dos diferentes grupos e classes sociais.

Todavia, a exemplo dos outros dois enfoques anteriores, o enfoque centrado em coalizões também apresenta suas limitações. Nas palavras de Hall, ficam em aberto as indagações sobre como esses grupos sociais definem especificamente seus interesses. Ou seja, esse enfoque não permitiria especificar o modo concreto como os conteúdos particulares dos diferentes membros das coalizões de apoio são construídos. Esse movimento de especificar a construção própria de interesses depende da incorporação de outras variáveis, como, por exemplo, o legado das políticas existentes e o impacto do desenvolvimento da teoria econômica e mesmo da avaliação da aplicação de certas idéias em outros contextos.

Embora apresentando aspectos problemáticos, os três enfoques oferecem perspectivas de análise bastante estimulantes do porquê da difusão das idéias e de seu impacto no plano das políticas adotadas pelos diferentes governos. Obviamente, cada uma delas privilegia determinadas dimensōes e conjuntos de atores, o que oferece uma pluralidade de razōes e de fatores para explicar a maior ou menor relevância das idéias keynesianas.

A síntese analítica proposta por Hall (1989) destaca que a influência de novos conjuntos de idéias econômicas tem sido examinada em termos de viabilidade administrativa, política e econômica. $\mathrm{O}$ autor destaca quatro fatores como os principais na explicação da difusão e dos impactos das idéias sobre as políticas públicas: a orientação do partido no governo, a estrutura do Estado e as relaçooes entre Estado e sociedade, a natureza do discurso político e o impacto de eventos externos.

A necessidade de adicionar outros fatores àqueles tradicionalmente evocados para explicar a recepção ou não de novas idéias está relacionada, de um lado, com a excessiva abrangência das questôes involucradas nas dimensões viabilidade econômica, administrativa e política, e, de outro, à necessidade de especificar um conjunto de fatores mais restritos que reforçam ou obstaculizam a adoção de políticas anticíclicas keynesianas.

O primeiro elemento, a orientação do partido no governo, é bastante reconhecido na ciência política para explicar certos arranjos ou configuraçôes institucionais. Dois exemplos bastante conhecidos são a associação entre a presença do neocorporativismo e a de partidos pro-labour no poder (cf. Cameron, 1984) e a relação entre a presença de governos socialdemocratas no governo e a adoção de políticas keynesianas (cf. Przeworski, 1989). Peter Hall retoma a importância da orientação ideológica do partido no governo 
2. Cabe aqui uma observação feita à luz da análise comparada sobre a difusão do keynesianismo. Há uma intrigante situação em que a introdução de políticas e idéias ligadas a Keynes é geralmente associada a partidos socialdemocratas, mas sua continuidade é obra de partidos conservadores. Os casos em que a iniciativa coube a partidos conservadores foram raros. A forte resistência verificada na Alemanha, na Itália e no Japão no pósguerra expressa a hegemonia de partidos conservadores, apoiando este argumento.

3. No caso do estudo sobre as idéias keynesianas, Hall menciona o poderdo Banco Central sobre as políticas públicas. A nosso ver, essa assertiva pode ser aplicada ao caso de outras áreas de políticas públicas, nas quais o poder poderá ou não estar concentrado nos órgãos ligados à política econômica. para explicar a difusão das idéias keynesianas. No período entre guerras, das cinco experiências keynesianas, apenas duas (Japão e Estados Unidos) não estiveram associadas à voz da classe trabalhadora, e sim ao esforço bélico. Por outro lado, a associação entre keynesianismo e socialdemocracia é muito evidente na experiência do Norte da Europa. Como mostra Pekkarinen (1989), o compromisso com as idéias keynesianas foi maior nos países em que havia hegemonia da socialdemocracia - Suécia e Noruega -, e bem menor onde não havia o mesmo vigor. Esse era o caso da Dinamarca, onde a coalizão política envolvia outros partidos políticos, e da Finlândia, onde a socialdemocracia era fraca. Apesar de ressaltar que não está afirmando a plena identidade entre socialdemocracia e keynesianismo, Hall considera um fator essencial para explicar a maior ou menor receptividade das idéias keynesianas nos diferentes países a existência ou não de robustos partidos socialdemocratas ${ }^{2}$.

O segundo elemento apresentado é a estrutura do Estado e as relaçóes entre Estado e sociedade. Por mais que os políticos possam ter qualidades de empreendedores, eles operam em determinadas estruturas institucionais estatais. $\mathrm{O}$ aspecto relevante é saber quais são as estruturas que recebem fluxos de recomendações, quais são os interesses dos decisores públicos com maior autoridade na formulação de políticas públicas no que diz respeito à dinâmica política e à capacidade técnica para implementar novas idéias em programas e políticas públicas. Três características da estrutura estatal seriam particularmente importantes para explicar a incorporação de novas idéias: 1) a permeabilidade dos funcionários públicos; 2) o grau de concentração do poder sobre as decisões da área de reforma concernida; e 3) o poder específico de um órgão ou agência governamental ${ }^{3}$.

Da mesma forma, as relações entre Estado e sociedade oferecem uma melhor especificação dos fatores e das condições de adoção de novas idéias e de seu impacto. Segundo Hall, o grande interesse sobre a estrutura do Estado deixou em plano secundário o estudo da dinâmica das relações entre Estado e sociedade. Essas relaçōes correspondem a redes institucionalizadas que organizam os fluxos de informação, os recursos e as pressões entre atores públicos e privados. Aqui estão presentes redes estabilizadas de intermediação de interesses e arranjos institucionais para a provisão de financiamentos públicos. Esse conjunto de relaçôes pode ter impacto positivo ou negativo sobre a capacidade do Estado de implementar certas políticas e, por isso, deve ser incorporado nas análises sobre o tema.

O terceiro elemento sugerido é a estrutura do discurso político. Essa variável aproxima-se do próprio conceito de referencial de políticas (cf. Jobert 
e Muller, 1987; Jenkins-Smith, 1993) e corresponde à existência de idéias ou de certo cluster delas, que exerce um papel de orientação tanto na definição dos diagnósticos como na delimitação das alternativas plausíveis e desejáveis.

$\mathrm{Na}$ formulação apresentada por Hall, trata-se de concepções acerca da natureza da sociedade e da economia, diferentes idéias sobre o papel apropriado do Estado e do governo, ideais comuns e a memória coletiva sobre experiências passadas. Um exemplo da pertinência de examinar as relações entre Estado e sociedade está no escrutínio público ao qual está submetido o conjunto de idéias novas quando essas são apresentadas como elementos inovadores e capazes de oferecer alternativas para problemas reconhecidos pela sociedade e pela opinião pública como graves e crônicos. À luz do caso das idéias keynesianas, lembra Hall, a natureza do discurso político dominante pode trabalhar como um elemento favorável ou desfavorável à introdução de novas idéias e propostas de políticas públicas.

As diferentes experiências nacionais em termos de planejamento e a diversidade dos modelos de Estado de Bem-Estar Social (cf. Esping-Andersen, 1990; Huber e Stephens, 2001) correspondem a distintos significados de experiências e de semântica política, que afetam por caminhos específicos a adoção de novas idéias e políticas. Por isso, um mesmo conjunto de idéias tende a adquirir pela natureza do discurso político nacional diferentes sentidos, que podem impulsionar, retardar ou bloquear sua difusão. Portanto, "como a estrutura do Estado ou a orientação do partido no governo, a natureza do discurso político nacional pode ser decisiva para que um novo conjunto de políticas seja aceito" (Hall, 1989, p. 383).

Como discutiremos mais adiante, a hipótese da existência do mecanismo do processo de aprendizado e mimicking (cf. Hemerijck e Visser, 2001) na difusão de idéias e de desenhos de novas políticas públicas introduz novos elementos ao argumento defendido por Hall. Por exemplo, a forte difusão de metodologias do tipo "melhores práticas" e de benchmark ${ }^{4}$ por organismos internacionais tem induzido a esse tipo de mecanismo de aprendizado e de imitação, mesmo quando adotada com prudência e seguindo uma orientação seletiva.

O quarto e último fator é o impacto de eventos externos, como a Segunda Guerra Mundial. A natureza desse elemento é bastante diversa dos três primeiros porque se trata de eventos que dificilmente vão se repetir, embora, hoje, os chamados choques externos, como as crises financeiras, pareçam ter uma forte afinidade eletiva com a globalização capitalista. Mesmo assim, esses eventos parecem ser variáveis intervenientes em termos
4. Termo já bastante difundido e cuja tradução mais aproximada seria "padrões de qualidade". 
5. Ou, nas palavras do autor, "se o exemplo keynesiano demonstra que as idéias têm um poder real no mundo político, isto também confirma que elas não adquirem força independentemente da constelação de instituiçõos e interesses que já estavam presentes" (Hall, 1989, p. 390). do modelo explicativo em discussão. Uma analogia interessante entre os ditos choques externos e os impactos dos acontecimentos da Segunda Guerra Mundial está em que ambos parecem reforçar certas escolhas políticas. Fica em aberto o problema da relação entre a dinâmica interna e o modo como os eventos externos são traduzidos internamente. $\mathrm{O}$ que resta como tema para reflexão é saber se nas condições atuais houve uma modificação na dinâmica entre os eventos externos e seus impactos ou sua recepção interna nos diferentes países.

Em síntese, uma importante conclusão do amplo trabalho comparativo coordenado por Hall é a de demonstrar que o poder efetivo das idéias não pode ser dissociado dos arranjos das instituiçôes e dos diferentes interesses econômicos, políticos e sociais organizados 5 . No entanto, a observação de que a importância das idéias não pode ser tratada à revelia das configuraçóes de interesses e das instituiçôes é insuficiente. Há necessidade de qualificar em termos teóricos como essas relações se estabelecem e qual é a sua dinâmica, enfrentando um elenco bastante intrigante de questões tanto analíticas como empíricas, o que poderemos explorar com o trabalho de Gofas.

De maneira estilizada, Gofas (2001a) identifica dois modelos básicos utilizados para conceituar as relaçôes entre fatores materiais (interesses e instituiçôes) e idéias. O primeiro enfoque vê as idéias como resultado randômico, fruto das condições de incerteza e complexidade social, afirmando-se dessa forma a antecedência das idéias sobre os interesses. O segundo enfoque propõe uma relação na qual os interesses são anteriores, as idéias são variáveis de mediação, auxiliares nas explicações dos processos políticos cuja principal variável são as instituições.

A nova onda de estudiosos que tem resgatado a perspectiva a partir das idéias teria criado uma espécie de nova ortodoxia, a qual, seguindo o viés racionalista, separaria as idéias dos interesses, tratando-as como variáveis em competição, cujo peso metodológico deve ser escrutinado sistematicamente. Ademais, essa corrente institucionalista teria estabelecido um problemático primado ontológico das instituições. A sugestão teórica alternativa de Gofas é considerar a relação entre idéias e interesses como um processo de constituição simultânea ou mútua. A adoção desse axioma inicial traz como decorrência lógica a negação de um primado ontológico, seja dos interesses, seja das instituições. Segundo o autor, a superação do reducionismo contido na polarização idéias-interesses aponta para um enfoque em que "as idéias fornecem um quadro de trabalho no qual os interesses se definem ou se constituem" (Gofas, 2001a, 2001b). 
Nessa linha de argumentação, o papel das estruturas compartilhadas de conhecimento é oferecer uma explicação de como se conformam as motivaçōes dos atores, tanto em termos daquilo que é relevante como da escolha dos meios ou dos instrumentos para atingir os objetivos. Assim, no debate sobre a relação entre idéias e instituições, é possível identificar na literatura recente alguns esforços de pensar essa problemática partindo da premissa de que as idéias são como mapas e produtos da condição de incerteza dos processos políticos e sociais.

Assim, uma primeira corrente sustenta a anterioridade das idéias em relação aos interesses. As estruturas cognitivas teriam uma espécie de ordenação lógica causal, que permitiria identificar padrões causais transferíveis para as estratégias dos atores e consubstanciados no próprio desenho das políticas. As idéias desempenhariam a função de "guias para o comportamento", seja estipulando relaçôes causais, seja delimitando estratégias para alcançar os objetivos. Entre as debilidades desse enfoque está a ausência de uma explicitação do mecanismo explicativo da adoção de um conjunto de idéias em detrimento de outros. A desconsideração do contexto social no qual as idéias se desenvolvem leva a que sejam tratadas como entidades que flutuam livremente, tendo em mente o pressuposto de que as idéias têm propriedades que produzem efeitos causais.

Ainda entre as correntes que partem da antecedência das idéias sobre os interesses, merece atenção aquela organizada em torno do conceito de comunidades epistêmicas. Ao contrário da anterior, esta fornece um mecanismo de seleção das idéias e também insiste na importância do aprendizado sobre políticas, seja dentro de comunidades que compartilham políticas públicas, seja nas suas relações com os formuladores de políticas. Entretanto, também esse enfoque apresentaria pelo menos duas dificuldades analíticas importantes (cf. Gofas, 2001a, 2001b). A primeira é o tratamento das idéias como produtos aleatórios que respondem à situação de incerteza. A segunda é a afirmação de que os atores são "redutores da incerteza" na coordenação da lógica causal. A crítica de Gofas ao trabalho de McNamara (1998) sobre a União Monetária Européia (UME) parece pertinente; embora afirme a interconexão entre idéias e interesses, a autora afirma que as idéias são fatores críticos no campo da política monetária porque a gestão macroeconômica é afetada pelas condições de incerteza. Dessa forma, ela estabelece uma distinção em termos de períodos históricos e setores específicos da economia, nos quais haveria um maior peso das idéias em função da presença da incerteza. Em outras palavras, a assertiva de que há conexão 
entre idéias e interesses é abandonada, e a explicação se constrói ad hoc baseada em fatores contextuais.

Além disso, dado o caráter aleatório das idéias, elas são consideradas variáveis intervenientes. Para Gofas (2001a, 2001b), essa definição traria como implicaçôes teóricas sérios riscos de simplificações excessivas no papel desempenhado pelas idéias e estruturas cognitivas nos processos políticos, como por exemplo tomá-las como filtros cognitivos que dão o significado para as estruturas. A definição das idéias como variáveis ajuda a problematizar os processos de formação de interesses e de preferências, ao se deter nas bases materiais e no contexto social, mas também, em contrapartida, dificulta a exploração plena das potencialidades de um enfoque a partir das idéias.

Finalmente, a concepção do processo de aprendizado político como unidirecional das comunidades epistêmicas para os formuladores de políticas também seria uma visão reducionista. A principal objeção é a conseqüência dessa concepção unilateral: privilegiar a priori um conjunto de atores e de idéias em detrimento de outros. Novamente, defrontar-nos-íamos com a ausência de mecanismos explícitos de seleção de idéias e interesses, que conduziria a soluções metodológicas como a firmação do primado ontológico de idéias ou instituiçôes ou, então, a explicações contextualizadas associadas à necessidade de enfrentar os limites impostos pela incerteza.

O segundo enfoque, que parte do axioma de que as idéias são posteriores aos interesses, considera as idéias como "pontos focais". Nas palavras de Goldstein e Keohane (1993), "as idéias afetam as interaçôes estratégicas, seja contribuindo seja dificultando esforços conjuntos para atingir resultados mais eficientes, resultados que sejam pelo menos tão bons quanto o status quo para todos os participantes". Nessa perspectiva, "as idéias contribuem para resultados na ausência de um equilíbrio específico" (apud Gofas, 2001b). Na verdade, nesse enfoque as idéias concebidas como "pontos focais" podem desempenhar duas funçôes diametralmente opostas: ou permitem a definição de soluções cooperativas ou impedem que essas sejam atingidas.

A objeção mais relevante a esse enfoque está associada à afirmação de que o primado dos interesses sobre as idéias tem como conseqüência considerá-las uma dimensão exógena, o que leva à reiteração da visão dualista de interesses e idéias. Em outras palavras, o viés racionalista estaria sendo reintroduzido no momento em que o dualismo interesses-idéias é mantido. Finalmente, as idéias são, também, definidas como "elementos" 
dentro das instituições, como variáveis auxiliares, incluídas em cadeias causais institucionais, cuja dinâmica faz a mediação entre as idéias e os resultados das políticas públicas. Aqui as idéias são variáveis de mediação inseridas nas diferentes lógicas institucionais. São as instituições que afetam as políticas públicas, cabendo às idéias um papel secundário na explicação das performances das políticas. A explicação de por que certo conjunto de idéias é aceito enquanto outras são rejeitadas está na natureza dos arranjos institucionais, que serviriam como filtro de seleção das idéias mais aptas. Em outras palavras, as instituiçôes seriam filtros que determinariam quais idéias têm maiores chances de ser mais influentes.

$\mathrm{Na}$ perspectiva analítica elaborada por Gofas, a preocupação principal é, enfim, contestar a incorporação residual ou exógena das idéias nas explicações sobre as escolhas públicas, a definição e a implementação de políticas. Em termos analíticos, essa postura teórica está sintetizada na assertiva de que interesses e idéias se constituem reciprocamente, na rejeição das correntes que sustentam seja o primado das instituições, seja a antecedência das idéias sobre os interesses.

Paradigma de políticas públicas, aprendizado institucional e mimicking

A perspectiva do paradigma de políticas públicas trabalha com diferentes situaçôes típicas. A primeira delas corresponde aos períodos normais, nos quais o processo decisório, as mudanças e o paradigma permanecem inalterados, e as mudanças são de natureza incremental e evolucionista. $\mathrm{Na}$ segunda, referida aos períodos excepcionais (de mudanças e de reformas), a situação é totalmente diversa, porque há a contestação e a substituição dos princípios estruturantes dos paradigmas que delimitam as opçôes de políticas públicas, e nessas circunstâncias há uma reconfiguração dos objetivos políticos.

Essa perspectiva relativiza bastante o peso do legado institucional das políticas, sustentando que "uma política responde menos diretamente a condições sociais e econômicas do que às conseqüências de políticas passadas" (Hall, 1993, p. 277). Vale lembrar que o cálculo dos atores políticos é reflexivo e estratégico, afastando-se da visão instrumental do agente maximizador. Precisamente a lógica da ação estratégica dos atores incorpora o conceito de "aprendizado social", definido como "uma tentativa deliberada de ajustar os objetivos ou as técnicas de respostas políticas a experiências passadas e a novas informaçōes". O aprendizado social, portanto, 
ocorre "quando as mudanças políticas resultam de processos como esses" (Idem, p. 278).

Hall propõe um aprofundamento analítico pela distinção de diferentes níveis de aprendizado social. Três ordens de aprendizado social correspondem a três ordens de mudança política:

a) A de primeira ordem, na qual "as condições específicas dos instrumentos de políticas são modificadas, enquanto os próprios instrumentos (e mesmo os amplos objetivos das políticas) permanecem inalterados".

b) A de segunda ordem, na qual tanto o contexto como os instrumentos são alterados (embora ainda dentro de um contexto de objetivos estáveis).

c) A de terceira ordem, que corresponde à mudança do próprio paradigma de política e, portanto, do próprio processo de fazer políticas, diferentemente das mudanças de primeira e segunda ordem, que ocorrem dentro dos limites do processo normal.

Essa perspectiva inspirada na literatura do aprendizado social introduz explicitamente uma variante nova do papel dos processos de aprendizado externo dos atores exteriores no espaço nacional ou de imitação de políticas e programas públicos e de reformas. Essa é a análise apresentada por Hemerijck e Visser (2001) num artigo de título sugestivo, "Learning and mimicking: how European welfare states reform", que discute as relações entre aprendizado (do ângulo da política doméstica) e aprendizado externo ou de imitação (do ângulo do aprendizado oriundo de fora). $\mathrm{O}$ argumento central dos autores é que os fatores-chave do processo de aprendizado no âmbito das políticas domésticas (nacionais) são as idéias, o poder, os formuladores de políticas e as instituições do processo decisório público.

$\mathrm{Na}$ literatura há dois grandes enfoques que discutem as relações entre as mudanças de políticas, o aprendizado sobre as políticas e a imitação das políticas (mimicking). O conceito de rede de compartilhamento de políticas, cujas origens remontam aos trabalhos de Karl Deustch (1963), sobre a aplicação da teoria dos sistemas à ciência política, posteriormente desenvolvidos por diversos autores (cf. Hall, 1993; Sabatier e Jenkins-Smith, 1993; Olsen e Peters, 1996), sugere que os formuladores de políticas "aprendem liçōes de sucessos e fracassos de políticas anteriores, e usam essas lições e o novo conhecimento para lidar com novos problemas". Sob outra perspectiva, a literatura que discute os processos de transferência, imitação de políticas e difusão de políticas (cf. Rogers, 1962; Walker, 1969; Rose, 1993; Berry e Berry, 1999) 
sustenta que os formuladores de políticas examinam as melhores práticas e adotam os modelos ou os padrōes bem-sucedidos no exterior.

A importância do conceito de mimicking está diretamente associada ao papel crescente desempenhado por atores internacionais - instituiçōes multilateriais e supranacionais - na definição das agendas de reformas econômicas e sociais. Exemplos disso são os processos de internacionalização e de integração econômica regional, as facilidades de comunicação e as estratégias explícitas dos organismos multilaterais - a Organização Econômica para a Cooperação Desenvolvimento (OCDE), o Fundo Monetário Internacional (FMI), o Banco Mundial -, que têm ampliado sua atenção no monitoramento da difusão de prescrições de políticas nacionais orientadas para a adoção das diretrizes da Nova Gestão Pública, a desregulação do mercado de trabalho, a privatização dos sistemas de pensões e a introdução de competição administrada na área de saúde.

Hemerijck e Visser (2001) sustentam que os processos de aprendizado ${ }^{6}$ têm limites inerentes à sua própria lógica. Os autores insistem na existência de fortes ambigüidades nos processos de feedback, bem como na própria conceituação de experiências de sucesso e de fracassos. Os critérios de sucesso e fracasso são freqüentemente objeto de disputa e contestação, enquanto o feedback enfrenta os obstáculos da incerteza dos contextos institucionais e da dificuldade de atribuir os efeitos a uma determinada ação ou conjunto de iniciativas. Os exemplos são os mais variados; um bastante presente no debate europeu é sobre se a moderação salarial ou a redução da jornada de trabalho produzem uma elevação no emprego.

Além disso, a natureza política dos sistemas sociais impele para um aprendizado conservador, no qual os erros e equívocos são simplesmente cancelados. Do mesmo modo, os eleitores tendem a responder melhor aos erros das políticas do que a oportunidades perdidas pela não escolha de certas políticas públicas. As escolhas em condiçōes de racionalidade limitada são baseadas em tentativas e erros, que somente em situações de muita mobilização pública levam a um debate aprofundado do diagnóstico e das alternativas viáveis.

O aprendizado e a introdução de novas orientações de políticas públicas estão associados a choques externos ou a contextos de crise grave. A situação da Holanda no início da década de 1980 e a crise da lira italiana nos anos de 1990 são dois exemplos limites em que foi possível dar início a processos de concertação social inaugurando novas orientações no plano das relaçóes entre os atores - Estado, associações empresariais e sindicatos -
6. O aprendizado é definido como a "habilidade de detectar e corrigir erros, e melhorar o funcionamento dos sistemas sociais" (Olsen e Peters, 1996, p. 4). 
que conduziram a um aprendizado político inovador (cf. Visser e Hemerijck, 1997; Tapia, 2003; Baccaro, Carrieri e Damiano, 2002).

\section{Estado, sociedade e mudança nas reformas dos anos de 1990}

Embora sem enfrentar a problemática epistemológica do primado ou não das instituições, uma geração recente de estudiosos dos pactos sociais e das concertações sociais de segunda geração, na Europa, tem insistido na importância das interaçôes estratégicas e do processo evolutivo de construção de novos paradigmas políticos.

Essa concepção evolucionista do neocorporativismo enfatiza precisamente a capacidade dos atores, nas suas interaçôes, de encontrar soluçôes negociadas que permitam responder positivamente a constrangimentos externos ou dificuldades internas. A inovação no plano da ação e da estratégia pode ocorrer em condições econômicas adversas, como mostram os exemplos da Holanda e da Itália, nos quais a percepção dos riscos, mas também das oportunidades, foi fundamental para os resultados alcançados. No caso holandês, dificilmente a retomada da concertação social pode ser explicada de forma adequada lançando mão da hipótese de resgate das instituiçôes e das estruturas corporativas. É preciso introduzir algumas mediações para explicar de maneira consistente por que se rompe o imobilismo dessas estruturas durante os anos de 1970.

Assim, o processo de aprendizagem seria um elemento fundamental para explicar a superação do imobilismo, embora não devamos subestimar a análise da articulação dos interesses e os conflitos decorrentes da arbitragem assimétrica dos diferentes interesses. Esse repertório compartilhado de práticas e de visóes constitui elemento que afeta positivamente a lógica de operação das instituições, introduzindo alteraçôes nos seus comportamentos típicos. Visser, fazendo uma reflexão sobre os ensinamentos dos pactos sociais de segunda geração, afirma que "a característica mais interessante da concertação social é a possibilidade que ela oferece às partes de redefinir o conteúdo de suas estratégias sob o ângulo do interesse coletivo" (Hemerijck e Visser, 2001, p. 52). O aprendizado aqui dependeria basicamente das características organizacionais e da relação de confiança mútua entre os atores, mesmo numa situação de relações assimétricas e de troca política pouco redistributiva no curto prazo.

Indiscutivelmente, a obra mais influente sobre a experiência de concertação social holandesa das últimas décadas foi o livro A Dutch Miracle 
de Visser e Hemerijck (1997). Do ponto de vista teórico, a hipótese desses autores é que houve uma "combinação entre gravidade dos problemas, transição de poder, instituiçōes, política e idéias" (1997, p. 12). Particularmente, a dimensão concertativa da economia holandesa não só teria auxiliado na implementação das políticas negociadas entre os agentes sociais e o Estado como facilitado a introdução de inovações tanto no conteúdo das propostas como no comportamento estratégico dos atores.

Aqui se explicita o argumento teórico nuclear dos autores: a estrutura corporativa e as práticas de concertação dos anos de 1980 teriam sido fundamentais para uma reorientação substantiva no conteúdo das negociações entre os agentes sociais e no próprio comportamento estratégico de confederações empresariais e sindicais. A combinação de aprendizado institucional voltado para soluções concertadas e uma robusta tradição da democracia consensual numa conjuntura crítica, a de 1982, seria a alma do milagre holandês. O processo de aprendizagem é aplicado a três âmbitos: relaçôes industriais, proteção social e mercado de trabalho. Os problemas e as soluções nessas três áreas - formação de salários, política social e mercado de trabalho - foram se interconectando. No começo dos anos de 1980, teria havido uma reviravolta nessas três áreas de decisão política, que passaram a se reforçar e articular entre si.

Em primeiro lugar, a decisão de adotar uma política de moderação salarial veio como resposta aos problemas de adaptação da economia holandesa à nova ordem econômica internacional. Segundo Visser e Hemerijck, a moderação salarial ajudou a baixar os custos do trabalho e a melhorar a competitividade dos preços dos produtos holandeses no mercado internacional. Os principais resultados positivos atribuídos à moderação salarial foram o crescimento do emprego, a recuperação das margens de lucro das empresas e o aumento dos filiados aos sindicatos e às confederaçóes. Esses resultados reforçaram a confiança entre os parceiros sociais, ampliando os apoios entre os membros das confederações à orientação pró-moderação salarial.

Em segundo, a reforma da proteção social, que começou com o congelamento dos benefícios e a revisão do seguro desemprego e, posteriormente, se estendeu às mudanças nas pensões por invalidade e seguro doença. Essas reformas, diversamente da moderação salarial, enfrentaram a resistência dos sindicatos. Ao mesmo tempo, no caso da proteção social, houve uma redução na participação dos parceiros sociais na gestão dos programas sociais. Assim, contrastando com o que ocorreu nas relaçôes industriais, no campo da proteção social houve uma considerável descontinuidade institu- 
cional e forte oposição entre o governo, de um lado, e as confederações patronais e sindicais, de outro.

Em terceiro lugar, a introdução de políticas inovadoras no mercado de trabalho, com destaque para o combate ao desemprego juvenil de longa duração. $\mathrm{O}$ governo adotou uma orientação voltada para o aumento da taxa de participação no mercado de trabalho, insistindo em que a solução para a crescente pressão fiscal enfrentada pelo Estado de Bem-Estar Social estava no estímulo ao crescimento do emprego, como forma de reduzir a pressão sobre o gasto social público. Para obter a ativação do mercado de trabalho, o governo lançou mão, com resultados desiguais, de diferentes mecanismos: redução dos salários (salário mínimo legal) nas negociações coletivas, reforma das agências públicas de emprego e autorização para o funcionamento de agências privadas de emprego.

Ao longo do tempo, as mudanças nesses diferentes âmbitos foram se reforçando e produzindo resultados positivos, permitindo arbitrar as perdas de setores do funcionalismo público e de grupos sociais ligados aos programas de pensão por invalidez, além de criar uma coalizão de apoio à estratégia de reforma concertada da economia holandesa.

$\mathrm{Na}$ interpretação de Visser e Hemerijck, a existência de estruturas corporativas e da tradição de negociação que exprime uma lógica política consorcionista é condição necessária, porém não suficiente, para explicar a guinada vivida pela Holanda. O retorno da estratégia de concertação foi resultado dos sinais emitidos pelo mercado - particularmente as elevadas taxas de desemprego - e da erosão do poder contratual das confederações sindicais no início da década de 1980 . A política de moderação não começou com o consenso, mas produziu o consenso. A origem da troca política entre confederaçôes patronais e sindicais esteve amparada na combinação de moderação salarial e redução gradativa da jornada de trabalho. No entanto, como reconhecem os autores e enfatizam seus críticos, apenas nos anos de 1990 é possível falar de resultados positivos das políticas de moderação salarial.

Então, como explicar a adesão à negociação concertada nos anos de 1980, nos quais havia uma situação econômica deteriorada e o Estado fez um severo ajuste no setor público cortando pessoal, reduzindo benefícios e gastos públicos?

Segundo Visser e Hemerijck, as principais razões da adesão dos sindicatos durante essa década foram a adesão de novos membros e a criação de novos postos de trabalho. A essas razões se aduziria o papel exercido pelo 
governo, denominado "sombra da hierarquia", isto é, a possibilidade de intervenção nas relações entre os agentes sociais, em caso de "necessidade", pelo Estado.

Ao mesmo tempo, embora não explicitamente, os autores sugerem que a percepção de riscos numa conjuntura econômica e política desfavorável impulsionou mudanças nas preferências estratégicas das lideranças sindicais. Em circunstâncias históricas particulares, uma crise cria um sentido de urgência e necessidade, e funciona como iniciador de aprendizado social e de mudança política. Na conjuntura do início dos anos de 1980, a principal mudança de mentalidade e política teria sido a de identificação do aumento de rentabilidade como condição para elevação dos investimentos, condição essencial para criar empregos e combater o desemprego.

Certamente, o argumento do caráter inovador das estratégias das confederaçôes sindicais prescinde da hipótese do ator racional, porque essa decisão pode ser justificada em termos de experimentalismo e percepção de riscos diante de um quadro no qual as opções adotadas por um certo período não produziram resultados satisfatórios. Além disso, a inexistência de resultados econômicos salientes no curto prazo torna pouco atraentes as explicações centradas numa lógica pragmática e maximizadora. Ou seja, parece improvável associar as opções estratégicas das confederações sindicais à teoria da escolha racional, ao menos nas suas vertentes mais ortodoxas.

$\mathrm{Na}$ verdade, os ingredientes básicos mencionados no clássico trabalho de Katzenstein (1985) estão presentes no esquema interpretativo de Visser e Hemerijck: a ideologia compartilhada dos parceiros sociais sobre as vantagens das decisões conjuntas; a existência de uma coordenação voluntária, muitas vezes informal, por meio de uma contínua consulta entre as organizações de representação de interesse, burocracia estatal e partidos políticos.

Dados os enormes desafios colocados pela reforma do Estado de Bem-Estar Social, incluindo-se aí o mercado de trabalho, o consenso social é um recurso estratégico para responder aos atores com capacidade de veto e às coalizões anti-reforma (cf. Pierson, 2001). As estratégias concertadas teriam essa vantagem sobre aquelas impositivas, que introduzem riscos maiores de bloqueio e de agudos conflitos políticos. Em contraste com a via impositiva das reformas do Estado social, o exemplo holandês mostra as vantagens da concertação e negociação social como mecanismo básico de elaboração e implementação das mudanças socioeconômicas. Ou seja, nas palavras dos autores, "[...] identificamos o papel central da concertação entre organizaçôes [de interesses] altamente coor- 
denadas para o desenvolvimento e a implementação de estratégias eficazes e prolongadas de adaptação da economia nacional - empresas e trabalhadores - no nível mais elevado de competição internacional” (Visser e Hemerijck, 1997, p. 205).

Apesar de insistirem nas vantagens da estratégia de concertação, Visser e Hemerijck falam de uma reconquista da concertação após o bloqueio dos anos de 1970. Na verdade, o argumento desenvolvido aqui é mais complexo do que deixa transparecer a comparação entre a imposição versus a concertação. Por quê? Basicamente porque as instituições de concertação não garantem per se a implementação de estratégias eficazes e contínuas tanto de reajustamento da economia holandesa ao novo cenário da globalização capitalista como de redefinição das relações industriais.

Como Ebbinghaus e Hassel (1999) e Hassel (2003) mostram, dependendo de um conjunto de condições institucionais e políticas, as estratégias de concertação podem produzir como resultados coalizões virtuosas ou colusões particularistas.

No caso holandês, a capacidade de renovação das estruturas corporativas nascidas no pós-1945 foi fortemente afetada pelos sinais negativos do mercado, os quais incentivaram os principais atores a rever suas percepçóes e modalidades de ação. Os resultados alcançados durante os últimos vinte anos - forte e consistente recuperação dos níveis de crescimento econômico e aumento da taxa de participação no mercado de trabalho e do emprego de tempo parcial - criaram um mecanismo de feedback que reforçou a legitimidade e o apoio dos atores sociais. O resultado foi a criação de condiçōes políticas para avançar na reforma do Estado de Bem-Estar Social nos anos de 1990, com graus de conflito político e resistências de grupos organizados relativamente modestos.

Visser e Hemerijck procuram distância da versão mediática do sucesso

7. Modelo holandês de negociação tripartite, datado do início dos anos de 1980, que tem lugar no Conselho Econômico Social e tem produzido muitos acordos entre capitalistas e trabalhadores ao longo dos anos. holandês sintetizada na noção de "Polder Model", amplamente difundida pelos meios de comunicação e pelo próprio governo holandês. A esse respeito, dizem os autores:

[...] não foi em nenhum momento um grande projeto, tampouco um plano geral ou uma troca política de grande envergadura, dos quais derivaram as políticas adotadas. A via holandesa de ajustamento e reforma está envolvida em muitos imprevistos: uma forte recessão, uma mudança no equilíbrio entre capital e trabalho, uma crise resultante de uma crescente inatividade e mudança no cenário político (1997, p. 208). 
Em síntese, a interpretação de Visser e Hemerijck está apoiada na idéia de que "a mudança na política é resultado de um desafio, o processo de identificação e definição de problemas e de soluções por parte do Estado e dos atores coletivos, e de construir poder, um processo de legitimação e mobilização de apoios por que certos problemas e soluções foram selecionados" (1997, pp. 13-14). Contudo, a estratégia corporativa teria limites bem precisos. Os arranjos institucionais corporativos não são suficientes para a efetividade das suas políticas porque estas dependem da existência de uma cultura política consensual, incluindo-se um compromisso dos principais jogadores com o interesse comum. E este é freqüentemente enviesado pelas relações assimétricas de poder e pelas interpretações dominantes sobre sua natureza, dinâmica e resultados.

Do ponto de vista do debate europeu sobre a natureza e as condiçóes de sustentabilidade das concertaçôes de segunda geração, há um forte ceticismo acerca das virtudes da chamada crítica à interpretação do corporativismo competitivo (cf. Ferrera et al., 2000). Como argumentavam Uwe Becker e Vergunst, o conceito de corporativismo competitivo construído sob inspiração do exemplo holandês, envolvendo uma política prolongada de moderação salarial, como defendido por vários economistas políticos (cf. Ferrera et al., 2000), não é uma opção viável.

A forte assimetria a favor dos empresários na relação com as confederações sindicais, o papel impositivo desempenhado pelo Estado e as derrotas sofridas ao longo do período explicariam em grande parte a adesão das lideranças sindicais às políticas de moderação e de reforma do Estado de BemEstar Social. Em vez de um processo de aprendizado institucional e da mudança de paradigma cognitivo, teria havido uma acentuada assimetria na correlação de forças a favor das confederaçôes empresariais e do Estado (cf. Becker, 2001). Na verdade, embora predomine uma visão de que o corporativismo e a democracia consensual holandesa têm raízes numa autonomia dos parceiros sociais, haveria uma forte imposição estatal, que parece ser reconhecida por Visser e Hemerijck quando dizem que não há um corporativismo forte sem um Estado forte.

\section{Considerações finais}

A reflexão desenvolvida partiu de uma insatisfação com a tendência das análises sobre os processos de reforma econômica e social de navegar numa dicotomia analítica entre instituiçôes e interesses, de um lado, e idéias ou 
paradigmas cognitivos, de outro. Embora bastante estilizada, essa dicotomia está presente numa parte ponderável dos estudos recentes.

Como vimos, há no debate internacional sobre o tema uma clara tentativa de superar essa polarização entre instituições, interesses e idéias. Ora colocando em xeque os diferentes enfoques institucionalistas, ora buscando incorporar de maneira não instrumental o papel das idéias e dos paradigmas cognitivos no próprio processo de constituição dos atores, reservando ao aprendizado social um papel importante, ao mesmo tempo em que ele é pensado como nascendo da interação e da negociação e da busca de regulação dos conflitos.

O debate contemporâneo nas ciências sociais tem buscado superar tradiçōes clássicas, seja na ciência política, seja na economia, sobretudo por meio da "redescoberta das instituições" e da incorporação da dimensão cognitiva dos processos políticos e dos atores nas suas interaçôes estratégicas.

Da perspectiva do novo institucionalismo na ciência política, a relação entre instituiçōes, interesses e idéias, ou paradigmas cognitivos, é vista do prisma do primado das instituiçôes. São elas que conformam as preferências ou os interesses, estruturam o campo das escolhas e determinam a própria dinâmica. Certamente, as nuanças e diferenças entre o institucionalismo da escolha racional, o aspecto sociológico e o histórico não são negligenciáveis (cf. Théret, 2003). Entretanto, ao menos no caso da concepção instrumental dos interesses presente nos enfoques da escolha racional, e mesmo naqueles culturalistas associados ao institucionalismo sociológico, parece haver pouco espaço para uma concepção que afirma a constituição simultânea dos interesses e das idéias, ou dos referenciais cognitivos. Há pelo menos duas ordens de argumentos para apoiar essa observação. De um lado, na visão da escolha racional, as interações estratégicas supõem as preferências dadas, elas são a afirmação do cálculo, o qual é exógeno à interação, embora possa sofrer mudanças em situaçôes de jogos repetidos. De outro, no caso do institucionalismo sociológico, a ênfase é dada ao papel de controle da cultura, dos valores, os interesses tendem à inércia, exprimindo o peso da dependência de trajetória. E a ênfase na dimensão cognitiva é vista como sinônimo de institucionalização, entendida como as regras e as classificações que fornecem elementos para coordenar ações num contexto de racionalidade limitada e de incerteza.

Diante dessas concepções, o institucionalismo histórico oferece uma vantagem analítica: ele vê as instituições como mecanismos para regular conflitos de interesses, seja em função da sua diferenciação, seja devido às situaçôes de assimetria de poder. Apesar de afirmar o primado das institui- 
ções, essa corrente se indaga sobre aonde levam as orientações e quais as suas implicações (cf. Immergut, 1996). Nesse sentido, é possível uma aproximação dos esforços desenvolvidos por autores como Peter Hall a outros como Gofas e Sabatier, para integrar as dimensões cognitivas como elemento constitutivo da explicação dos processos políticos - formulação, implementação de políticas e programas -, buscando uma articulação entre interesses, instituições e idéias.

Para isso, os conceitos de aprendizado político e mimicking parecem ser bastante promissores, embora, como observamos, haja necessidade de uma reflexão mais sistemática e acurada, tendo como foco as experiências concretas de reformas econômicas e sociais.

Do ponto de vista metodológico, as sugestôes de Gofas parecem contribuições relevantes. Três questões-chave organizam a análise da relação entre idéias, interesses e instituições:

1) Quais são as idéias transferidas ${ }^{8}$, isto é, aquelas que estão em disputa, refletindo diferentes concepções sobre determinados problemas que orientam diagnósticos e delimitam o campo das alternativas plausíveis ${ }^{9}$, que fornecem modelos de relações causais etc.

2) Quem transfere as idéias? Quais os atores e as instituições que difundem as idéias dominantes ou as estruturantes, e por quais mecanismos? Aqui podemos trabalhar a noção de diferentes constelações de atores (cf. Scharpf, 1997) ou de comunidades de políticas situadas no plano nacional ou internacional, que interagem dentro de uma lógica de redes de compartilhamento de políticas (cf. Kenis e Schneider, 1991).

3) Finalmente, como as idéias são transferidas? Os mecanismos podem ser a emulação ou o aprendizado social. Aqui são cruciais as interações estratégicas reiteradas que se dão em arenas específicas (reuniōes periódicas, conselhos etc.).

É preciso lembrar que as reformas políticas são muito dependentes de diagnósticos efetivos e do papel das idéias na competição pelo poder. Uma reorientação política requer uma coalizão de reivindicações, que mina considerações judiciosas sobre a experiência de fazer políticas. Os exemplos empíricos apresentados na terceira parte deste trabalho oferecem, a nosso ver, alguns insights que merecem ser mais bem avaliados.

Como mostram Visser e Hemerijck (1997), as interaçôes estratégicas, quando inseridas em arenas decisórias estáveis, podem estimular inovações
8. Por idéias estamos considerando estruturas de conhecimento que desempenham as funções de organizar e informar os formuladores de políticas sobre determinado problema.

9. $\mathrm{Na}$ formulação de Jenkins-Smith, elas correspondem aos sistemas de crenças, isto é, a "um conjunto de valores prioritários e pressupostos causais sobre como realizá-los" (1993, p. 16) dos programas e políticas.

junho 2008 
tanto no plano dos objetivos como no dos instrumentos, dentro de um quadro institucional estável. A trajetória da concertação social na Holanda interpela a hipótese do peso inercial das instituiçôes porque, num contexto externo de crise aguda e de paralisia decisória, foram as decisões estratégicas dos principais atores envolvidos que levaram à superação da situação de impasse. Vale lembrar que a política de concertação nos anos de 1980 não começou de maneira consensual, mas levou à construção de um consenso sobre as soluções para graves problemas ligados ao mercado de trabalho e ao Estado de Bem-Estar Social.

Os conflitos e as divergências não desapareceram; tampouco devemos esquecer as relações assimétricas entre as organizaçōes empresariais e sindicais no período. Não obstante essa situação adversa, a percepção dos riscos envolvidos, incluindo-se aí a alternativa de uma intervenção unilateral do Estado, induziu os atores sociais a modificarem seu padrão de comportamento, buscando soluções novas para os agudos problemas econômicos e sociais da década de 1980. Na verdade, a experiência holandesa e também a italiana são coerentes com a hipótese de que em determinados momentos de dramáticas mudanças externas podem criar-se janelas de oportunidades para reformas e alteração de paradigma. Em suma, o corporativismo evolutivo sugere que sob determinadas condiçôes os processos de aprendizado institucional e social se desenvolvem contestando a lógica inercial das instituições, abrindo espaço para novos paradigmas de políticas, que se traduzem numa redefinição dos interesses dos atores, para os quais o jogo estratégico dos atores sociais é crucial.

\section{Referências Bibliográficas}

Baccaro, L., Carrieri, M. \& Damiano, C. (2002), "The resurgence of the Italian confederal union: will it last?”. ILO, DP 144. Labour and Society Programme.

Becker, U. (2001), "Competitive corporatism below sea level? Dutch myths and puzzles". Paper to be presented at the conference on Small States in World Markets Fifteen Years Later.

BerRY, F. S. \& BerRY, W. D. (1999), "Innovation and diffusion models in policy research". In: SABATIER, P. A. (org.). Theories of the policy process. Boulder, Co., Westview, pp. 169-99.

Cameron, D. (1984), "Social democracy, corporatism, labour quiescence and the representation of economic interests in advanced capitalist society". In: 
Goldthorpe, J. H. (org.). Order and conflict in contemporary capitalism. Oxford, Clarendon Press, pp. 143-78.

Crouch, C. H. (2001), "The crisis of keynesianism and the rise of neoliberalism in Britain”. In: Campbell, John L. \& Pedersen, Ove K. (orgs.). The rise of neoliberalism and institutional analysis. Princeton, Princeton University Press, pp. 193218.

Deutsch, K. W. (1963), The nerves of government: models of political communication and control. Nova York, Free Press.

Ebbinghaus, B. \& Hassel, A. (1999), "The role of tripartite concertation in the reform welfare state". Transfer, 1-2: 64-81.

Esping-Andersen, G. (1990), The three worlds of welfare capitalism. Cambridge, Polity Press.

. (1996), Welfare States in transition: national adaptations in global economies. Londres, Sage.

Ferrera, M., Hemerijck, A. \& Rhodes, M. (2000), The future of social Europe: recasting work and welfare in the new economy. Report for the Portuguese Presidency of the European Union. Oeiras, Celta Editora.

Gofas, A. (2001a), "Ideas and interests in the construction of EMU: beyond the rationalist bias of the new ideotional orthodoxy". CSGR Working Paper, University of Warwick, $36 \mathrm{pp}$. . (2001b), "Ideas and interests: research project".University of Warwick.

Goldstein, J. \& Keohane, R. O. (1993). "Ideas and foreign policy: an analytical framework". In: (orgs.). Ideas and foreign policy: beliefs, institutions and political change. Ithaca, Cornell University Press.

Gourevitch, P. (1986), Politics in hard times: comparative responses to economic crises. Ithaca, Cornell University Press.

Gualmini, E. (1995), "Apprendimento e cambiamento nelle politiche pubbliche". Rivista Italiana di Scienza Politica, XXV (2): 343-370.

Hall, P. (org.) (1989), The political power of economic ideas. Princeton, Princeton University Press.

. (1993), "Policy paradigm, social learning and the State: the case of economic policymaking in Britain”. Comparative Politics, 25 (3): 275-296.

. (1997), "The role of interests, institutions, and ideas in the comparative political economy of industrialized nations”. In: Lichback, Mark \& ZuCKerman, Alan (orgs.). Comparative politics: rationality, culture and structure. Nova York, Cambridge University Press, pp. 174-207

Hall, P. \& Taylor, Rosemary C. R. (1996), "Political science and the three new institutionalisms". Political Studies, 4 (5): 936-957. 
Hassel, A. (2003), "The politics of social pacts". British Journal of Industrial Relations, 41 (4): 707-726.

Heclo, H. (1974), Modern social politics in Britain and Sweden: from relief to income maintenance. New Haven, Yale University Press.

HemerijcK, A. \& VisSER, J. (2001), "Learning and mimicking: how European welfare of leyden”. University of Leiden/University of Amsterdam.

Huber, E. \& Stephens, J. D. (2001), Development and crisis of the welfare State: parties and policies in global markets. Chicago, University of Chicago Press.

IMMERGUT, E. M. (1996), “The normative roots of the new institutionnalism: historicalinstitutionalism and comparative policy studies”. In: BENZ, A \& SeIBEL, W. (orgs.). Beiträge zur Theorieentwicklung in der Politik und Verwaltungswissenschaft. BadenBaden, Nomos Verlag.

JaCOBSEn, J. K. (1995), "Much Ado about ideas: the cognitive factor in economy policy". World Politics, 47: 283-310.

Jobert, B. \& Muller, P. (1987), L'État en action. Paris, PUF.

KatZenstein, P. (1985), Small States in world markets: industrial policy in Europe. Ithaca, Cornell University Press.

Kenis, P. \& Schneider, V. (1991), "Policy network and policy analysis; scrutinizing a new analytical toolbox”. In: Marin, B. \& MAYNTZ, R. (orgs.). Policy networks: empirical evidence and theoretical considerations. Frankfurt, Campus Verlag/Westview Press, pp. 25-62.

MCNAMARA, K. R. (1998), “The currency of ideas: monetary politics in the European union”. Ithaca, Cornell University Press.

Mesa LAGo, C. (2001), "Structural reform of social security pensions in Latin America: models, characteristics, results and conclusions". International Social Security Review, 54 (4): 67-92.

Molina, O. \& Rhodes, M. (2002), "Corporatism: the past, present, and future of a concept". Annual Review of Political Science, 5: 305-331.

Olsen, J. P. \& Peters, G. (1996), Lessons from experience: experiential learning in administrative reform in eight democracies. Oslo, Scandinavian University Press.

Pekkarinen, J. (1989), "Keynesianism and Scandinavian models of economy policy”. In: Hall, P. (org.). The political power of economic ideas. Princeton, Princeton University Press.

PIERSON, P. (2001), "Coping with permanent austerity: welfare State restructuring in afluent democracies". In: . (org.). The new politics of the welfare State. Oxford,

Oxford University Press, pp. 410-456.

Przeworski, A. (1989), Capitalismo e socialdemocracia. São Paulo, Cia. das Letras.

Rogers, E. E. (1962), Diffusion of innovations. Nova York, The Free Press. 
Rose, R. (1993), Lesson-drawing in public policy: a guide to learning across time and space. Chatham, NJ, Chatham House Publishers.

Sabatier, P. A. \& Jenkins-Smith, H. C. (orgs.) (1993), Policy change and learning: an advocacy coalition approach. Boulder, Co., Westview Press.

SALANT, Walter. (1989), "The spread of keynesian doctrines and practices in the United States". In: Hall, P. (org.). The political power of economic ideas. Princeton, Princeton University Press, pp. 27-51.

SCHARPF, F. (1997), Games real actors play: actor-centered institutionalism in policy research. Boulder, Co., Westview Press.

TAPIA, J. R. B. (2003), "Concertação social, negociações coletivas e flexibilidade: o caso italiano (1992-2002)”. Revista Dados, 46 (2): 215-264.

ThérEt, B. (2003), "Instituições entre as estruturas e as ações”. Lua Nova, 58.

VisSER, J. (1998), “Concertation: the art of making social pacts”. In: Delors, J. et al. (orgs.). National social pacts: assessment and future prospects. Bruxelas/Paris, European Trade Union Institute/Notre Europe.

VisSER, J. \& HeMERIJCK, A. C. (1997), “A Dutch miracle”: job growth, welfare reform, and corporatism in the Netherlands. Amsterdam, Amsterdam University Press.

WalKer, J. L. (1969), "The diffusion of innovations among the American States". American Political Science Review, 63: 880-899.

Weir, M. \& Skостоl, T. (1985), "States structures and the possibilities for keynesian responses to the great depression in Sweden, Britain and United States". In: Evans, P. et al. (orgs.). Bringing the State back in. Nova York, Cambridge University Press, pp. 107-168.

\section{Resumo}

Idéias, interesses e mudanças institucionais

Este artigo é uma discussão das relações entre instituições, interesses e idéias, tendo como referência empírica as experiências de concertação social na Europa e as reformas da previdência social na América Latina dos anos de 1990. Reconhecendo que o debate atual sobre essas reformas tem incorporado a importância da dimensão cognitiva dos processos políticos na tentativa de construir abordagens mais complexas e adequadas sobre os fenômenos em pauta, diferentemente das análises anteriores com essa preocupação, argumentamos que a ênfase dada ao papel das idéias até agora ainda não parece ser suficiente para explicar a natureza e a difusão dos processos de reformas econômicas e sociais, sua legitimidade ou sustentação política. É preciso que o processo de adoção das idéias produza resultados avaliados positivamente, oferecendo respostas, mesmo que não consensuais, para questôes consideradas centrais na agenda 
Texto recebido em 6/ 4/2006 e aprovado em $11 / 1 / 2008$.

Jorge R. B. Tapia é professor do Instituto de Economia da Unicamp ecoordenador dos Centros e Núcleos da Unicamp.E-mail:bitapia@ reitoria.unicamp.br.

Eduardo Rodrigues Gomes é professor do Programa de Pós-Graduação em Ciência Política da Universidade Federal Fluminense. E-mail: gomeser@oi. com.br. pública. Além disso, há um complexo processo de aprendizado e de mimicking no âmbito das políticas sociais que permite elucidar alguns dos seus intrincados desdobramentos, fazendo com que estes elementos não possam ser desconsiderados, inclusive porque talvez permitam adicionar novas dimensões às abordagens das reformas econômicas e sociais inspiradas nas instituições ou na competição política.

Palavras-chave: Neoinstitucionalismo; Idéias; Interesses; Aprendizado político; Concertaçôes sociais.

\section{Abstract}

\section{Ideas, interests and institutional changes}

This article discusses the relations between institutions, interests and ideas, taking as its reference point experiences in social concertation in Europe and welfare system reforms in Latin America in the 1990s. Recognizing that the current debate over these reforms has incorporated the importance of the cognitive dimension of political processes as a way of building more complex and adequate approaches to the phenomena in question, we take a different approach to previous analyses, arguing that the emphasis given up to now to the role of ideas is insufficient to explain either the nature and diffusion of the processes of economic and social reforms, or their legitimacy and political support. The process of adopting ideas has to produce results that are positively assessed and offer answers - whether consensual or not - to questions deemed central to the public agenda. In addition, there is also a complex process of policy learning and mimicking that allows for better understanding of complex developments, expressing the fact that these elements cannot be left out of the explanations, since they may add new dimensions to studies of economic and social reforms inspired by the role of institutions or by political competition.

Keywords: Neoinstitutionalism; Ideas; Interests; Political learning; Social concertation. 